\title{
Influence of SiC Content on Microstructure, Dislocation Density and Mechanical Behavior of $\mathrm{Cu} / \mathrm{SiC}$ Composite
}

\author{
H. A. EL-Fattah ${ }^{1,4^{*}}$, M.A. Metwally ${ }^{2,}$, M. M. Sadawy ${ }^{1}$, I .G.El-Batanony ${ }^{3}$ \\ ${ }^{1}$ Mining and Pet. Dept, Faculty of Engineering, Al-Azhar University, Nasr City, \\ Egypt \\ ${ }^{2}$ Egyptian Natural Gas Company (GASCO), Cairo, Egypt \\ ${ }^{3}$ Mech.Eng.Dept.Faculty of Engineering, Al-Azhar University, Nasr City, Cairo, \\ Egypt \\ ${ }^{4}$ Alexandria Higher Institute of Engineering and Technology (AIET), Alexandria, \\ 21311, Egypt \\ ${ }^{1}$ Email id:hasanfattahy2008@yahoo.com, ${ }^{4}$ Email id: mtayea00@ gmail.com, ${ }^{1}$ Email: \\ mosaadsadawy@yahoo.com, ${ }^{3}$ Email id: ibatanony@yahoo.com
}

\begin{abstract}
The present investigation has examined the impact of micro-SiC on microstructure, dislocation and mechanical behavior of $\mathrm{Cu} / \mathrm{SiC}$ composite. The micro-composite samples have been fabricated under a constant pressure (480 $\mathrm{MPa})$ and sintered temperature $(860 \mathrm{oC})$ for $2 \mathrm{~h}$. The sintering process was performed under argon gas. The microstructure examination was conducted using SEM/EDS and XRD diffraction. The SiC contents were 0, 5, 10,15,20,25 and 30 volume fraction. The outcomes showed that the density was significantly decreased with an increase of silicon carbide content. The relative densities of $\mathrm{Cu}$ and $\mathrm{Cu} / \mathrm{SiC}$ composites was ranged from $91.24 \%$ to $83.56 \%$ for pure $\mathrm{Cu}$ and $\mathrm{Cu} / 30$ vol\% SiC composites. The copper crystallite size was reduced with growing SiC content while the hardness, ultimate and yield compressive strength increased with increment of SiC volume fraction to $20 \%$ vol. The values of hardness, ultimate and yield compressive strength increased to $231 \mathrm{HV}, 343$ and $176 \mathrm{~N} / \mathrm{mm} 2$, respectively for the composite sample containing $20 \%$ SiC particles with a percentage increase of $75 \%, 26.6 \%$ and $57.2 \%$ compared with pure $\mathrm{Cu}$.
\end{abstract}

\author{
Keywords: Powder metallurgy, Composites, grain size, Dislocation density, \\ Compressive strength
}

* Corresponding author.

E-mail address: hassanfattahy2008@yahoo.com (A.A. Atia). Tel:+2-1020682242 


\section{Introduction:}

Because of its outstanding electrical properties, thermal conductivity, corrosion resistance and ductility, copper is considered one of the most important metals in engineering applications [1-3]. The low strength of $\mathrm{Cu}$-matrix, on the other hand, is a severe issue that prevents copper from being used in many fields [4]. Cu-matrix composites have recently been demonstrated to be potential prospects in a number of high-tech applications, including railway overhead current collection systems and homopolar machines [3,4]. The possible reinforcements for the copper matrix include different types such as carbides, oxides, nitride and borides which have thermally stablability at high temperatures [5]. Because of its employment as reinforcement in matrix composites, SiC particles are of tremendous technological value.

Recently, $\mathrm{Cu} / \mathrm{SiC}$ composites have become a substantial investigation due to their outstanding thermal and electrical conductivity, high hardness values and wear resistance [6,3,7-9]. Efe et al [10] found that increasing $\mathrm{SiC}$ contents drops the electrical conductivity of $\mathrm{Cu} / \mathrm{SiC}$. Somani et al [11] found that increment of $\mathrm{SiC}$ to 20 mass \% enhances the mechanical properties of $\mathrm{Cu}$ due to increasing the interfacing between $\mathrm{SiC}$ and $\mathrm{Cu}$ particles while the density illustrated a reverse tendency. Metwally et al [7] reported that $\mathrm{Cu} / \mathrm{SiC}$ corrosion resistance was improved with increment of $\mathrm{SiC}$ content due to properties of the protective copper oxide films and reducing the microgalvanic couple between $\mathrm{SiC}$ and $\mathrm{Cu}$. Akbarpour et al [12] illustrated that the friction coefficient increased with growing $\mathrm{SiC}$ contents. Further they reported that the predominant wear mechanism was flake formation spalling and abrasion. However, with increment of $\mathrm{SiC}$ vol\% the flake formation spalling wear was reduced. On the other side, Prosviryakov [13] indicated that the increase of $\mathrm{SiC}$ concentration above 25 wt. \% lowers the hardness of $\mathrm{Cu} / \mathrm{SiC}$ composites by increasing porosity and decreasing microstructural homogeneity. Unfortunately, few studies have looked into the effects of $\mathrm{SiC}$ particles with a high volume $\%$ on the physical and mechanical properties of $\mathrm{Cu} / \mathrm{SiC}$ composites made by powder method. Therefore, this study was devoted to fabricate $\mathrm{Cu}$ with different volume fractions of $\mathrm{SiC}$ ranged from 0 to $30 \mathrm{SiC}$ (vol. \%) and investigate their effects on the microstructure, dislocation density and mechanical properties.

\section{Materials and Methods:}

\subsection{Materials:}

A high-purity copper metal with an average particle size of $10 \mu \mathrm{m}$, was used as the matrix, as well as $\mathrm{SiC}$ having 99.8 purity and average particle size of $3 \mu \mathrm{m}$, was used as reinforcement material to produce $\mathrm{Cu} / \mathrm{SiC}$ microcomposites. The powder mixtures were processed by a mixer with $10 \mathrm{~cm}$ diameter and speed of $950 \mathrm{rpm}$ for 3 hours and $\mathrm{Cu} / \mathrm{SiC}$ composites were fabricated with varied $\mathrm{SiC}$ particle volume fractions ( 0 to $30 \mathrm{vol} \%$ ). The powder mixtures with different volume fractions were compacted in a steel die with a $12 \mathrm{~mm}$ diameter at constant load of $400 \mathrm{MPa}$. SEM micrograph of copper and SiC particles and its EDS analysis were illustrated in Fig 1 (a \& b), respectively. After that the cold-pressed specimens were sintered at $850^{\circ} \mathrm{C}(80 \%$ of the melting point of $\mathrm{Cu})$ in the argon gas for 2 hours by electrical tube furnace with constant heating and cooling rate of $5 \mathrm{C} / \mathrm{min}$.

\subsection{Density determination}

According to ASTM B328 Standard, The density and relative density of $\mathrm{Cu} / \mathrm{SiC}$ composites were determined using Archimedes' principle. The theoretical density of the composites was calculated using a mixture rule as follows:

$$
d_{C}=d_{m} V_{m}+\rho_{r} V_{r}
$$


where $\mathrm{dm}, \mathrm{dr}$ and $\mathrm{Vm}, \mathrm{Vr}$ are the matrix and reinforcement densities and volume fractions, respectively. Also, the ratio of experimental and theoretical densities was used to calculate the relative density.
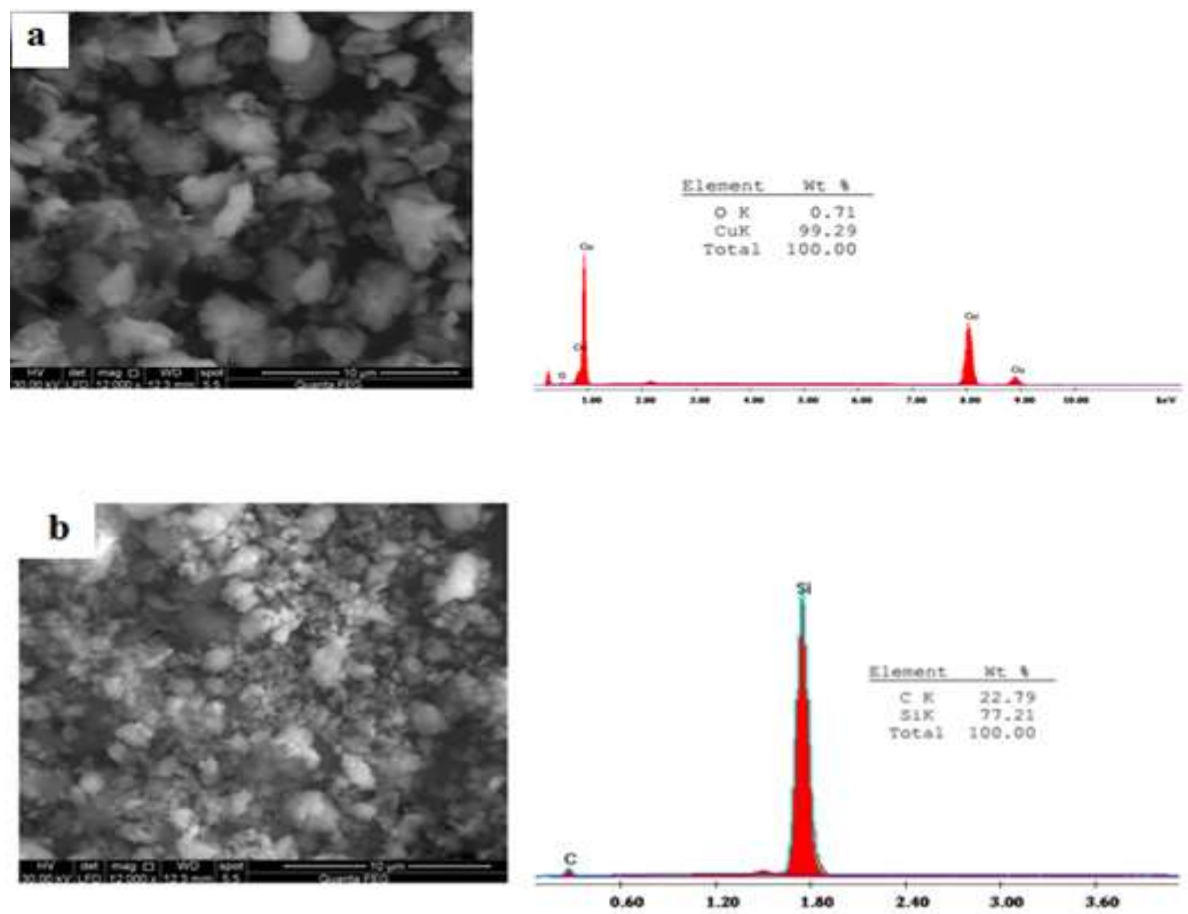

Figure 1. SEM Micrographs And EDX Analysis of (a) Copper (b) SiC particles.

The schematic diagram of $\mathrm{Cu} / \mathrm{SiC}$ microcomposites manufactured by powder metallurgy technique is shown in Fig. 2.

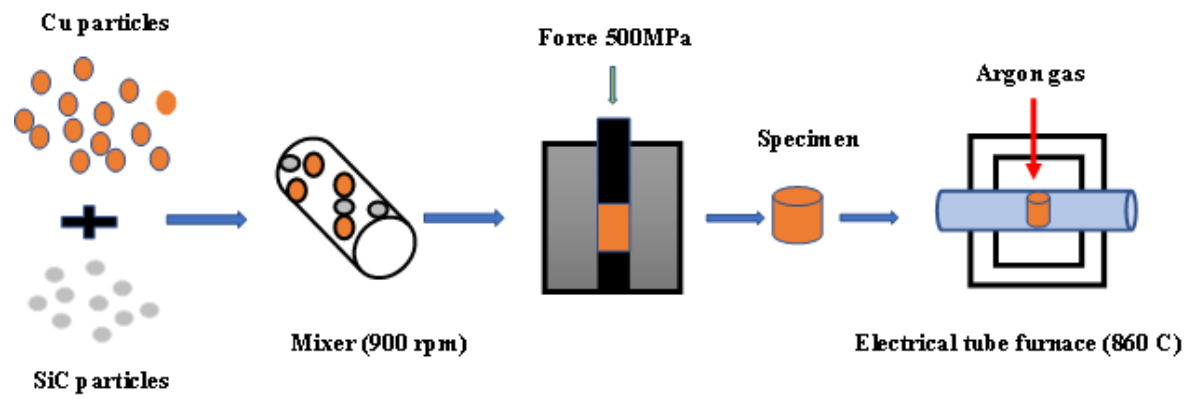




\section{Figure 2. Schematic Illustration Of Cu/SiC Microcomposites Produced By Powder Metallurgy Process.}

\subsection{Microstructural evaluation}

The microstructure, crystallite size, shape and distribution of $\mathrm{SiC}$ reinforcement were observed by JEOL (model JSM). No - (6330F) microscope at a voltage of $20 \mathrm{keV}$. All samples were prepared and grounded using 360, 600,1000 and 1200 grit -silicon papers. The specimens were mechanically polished with 6,3 and lum diamond paste after grinding, then etched in a solution of $5 \mathrm{~g}$ of $\left(\left(\mathrm{FeCl}_{3}+25 \mathrm{~mL} \mathrm{HC1}+50 \mathrm{~mL} \mathrm{H}_{2} \mathrm{O}\right)\right)$ to improve contrast. The existing of $\mathrm{SiC}$ particles and its dispersion on the copper matrix were seen at different magnifications on the specimens.

The distinct phases and crystallite sizes of $\mathrm{Cu}$ and $\mathrm{Cu} / \mathrm{SiC}$ microcomposite were calculated using $\mathrm{X}$ ray diffraction analysis on (Philips Machine). A monochromatic $\mathrm{Cu}-\mathrm{K}$ radiation with wavelength ( $\lambda$ $=0.154 \mathrm{~nm})$ ) has been used. The experiment was ran from angle of $5^{\circ}$ to angle of $90^{\circ}$, at $0.01^{\circ}$ step.

\subsection{Hardness test}

Hardness of $\mathrm{Cu} / \mathrm{SiC}$ composites was conducted on the polished surfaces without etching using digital metallic Vicker's hardness tester. The Vicker's test was performed on the surfaces of specimen with a $10 \mathrm{~kg}$ load applied for 15 seconds. The Vickers hardness values were shown as color-coded contour maps to demonstrate the hardness differences over the sample surface. A hardness indentations were made on each surface of specimen with a $0.5 \mathrm{~mm}$ distance between each individual point

\subsection{Compression test}

Compression specimens were cut from the unrienforced $\mathrm{Cu}$ and $\mathrm{Cu} / \mathrm{SiC}$ composites using a wire cutting machine. Compression testing was performed on $12 \mathrm{~mm}$ diameter and $10 \mathrm{~mm}$ height. The test was performed at an initial strain rate of $0.5 \mathrm{~mm} / \mathrm{min}$, using a testing machine (com-ten with program software 2.1.25). The compressive property data are based on the average of three individual tests on the three different samples. The tests were performed on the full disc specimen. The maximum failure load was determined by compressing the sample between two flat platens.

\section{Results and discussions:}

\subsection{Density measurements}

Fig. 3. illustrates the effect of $\mathrm{SiC}$ vol\% on the relative ,theoretical and experimental density of $\mathrm{Cu} / \mathrm{SiC}$ microcomposites. It is clear that increasing $\mathrm{SiC}$ particles declines $\mathrm{Cu} / \mathrm{SiC}$ microcomposites density. This result is similar to the results of Prosviryakov [13]. Further, Fig.. 3. Indicates that the relative density reduced from 91.3 (pure $\mathrm{Cu}$ ) to $83.56 \%$ with increasing $\mathrm{SiC}$ particles to 30 (vol \%). The high reduction in the relative density is attributed to the size and content of $\mathrm{SiC}$ according to the conclusion of Efe et al [10]. The density of $\mathrm{SiC}$ particles $\left(3.2 \mathrm{~g} / \mathrm{cm}^{3}\right)$ is substantially less than that of $\mathrm{Cu}\left(8.9 \mathrm{~g} / \mathrm{cm}^{3}\right)$, which explains this reduction in the density. The $\mathrm{Cu} / \mathrm{SiC}$ interface is high in composites with a high $\mathrm{SiC}$ content, resulting in a high copper atom diffusion barrier. The copper atoms were thus unable to easily disperse and seal the gaps between the $\mathrm{SiC}$ particles. Thus, compaction process is hindered [7]. 


\subsection{Microstructure evaluation}

Fig. 4 shows $\mathrm{SEM}$ images of $\mathrm{Cu} \& \mathrm{Cu} / \mathrm{SiC}$ microcomposites sintered at $860^{\circ} \mathrm{C}$ with various $\mathrm{SiC}$ volume fractions. These microstructure images reveal the existence of $\mathrm{SiC}$ in the composites, as well as the even dispersal of $\mathrm{SiC}$ micro particles within the matrix. Also, when the content of $\mathrm{SiC}$ particles is added to $20 \%$, the $\mathrm{SiC}$ particles move and concentrate at the grain boundaries, forming a homogenous network and uniformly dispersed inside the matrix as well. Like this behavior was obtained by Efe et.al [10]. Furthermore, Fig. 4 proves that as the SiC content augments, the size of grains for $\mathrm{Cu}$ - matrix decreased. The pinning effect of reinforcement, which restricts grain growth in the matrix, causes a decrease in $\mathrm{Cu}$ grains. However, at greater volume fractions, non-uniform $\mathrm{SiC}$ reinforcement particle distribution and $\mathrm{SiC}$ clusters were clearly visible (Fig 4 (f, g)). As the $\mathrm{SiC}$ particle volume fraction increased to 25 and 30 vol. $\%$, the clustering became more sharp as shown in (Fig. 4 (f,g)). It's worth noting that the removal of the reinforcing particles during sample preparation contributed to the formation of pores inside the necklace structure of SiC particles (Fig. 4(f, g)).

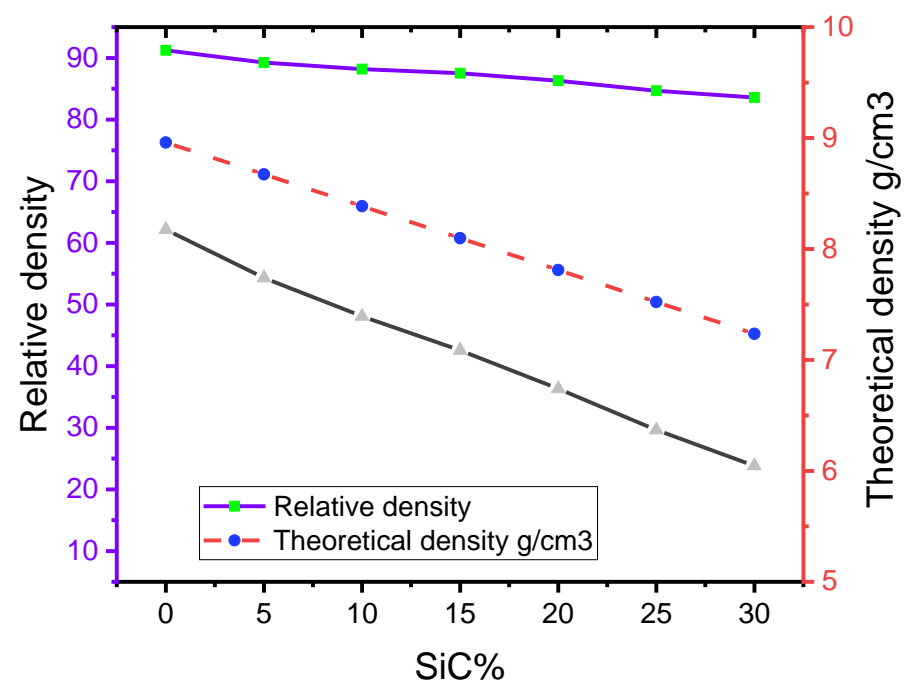

\section{Figure 3. Shows The Effect of SiC \% on The Relative, Theoretical And Experimental Density of $\mathrm{Cu} / \mathrm{SiC}$ Microcomposites.}

Distribution maps of the $\mathrm{Cu}, \mathrm{Si}$ and $\mathrm{C}$ elements in a SEM image of $\mathrm{Cu} / 20 \mathrm{vol} \% \mathrm{SiC}$ microcomposite obtained by EDS analysis and observed in the Fig. 5. As shown in the image with blue color, Cu may be seen covering practically the whole surface. Images with green and red color clearly showed $\mathrm{Si}$ and $\mathrm{C}$ elements are less than $\mathrm{Cu}$ element and that indicates existence of dispersed $\mathrm{SiC}$ in the $\mathrm{Cu}$ matrix. In addition, EDS analysis map reveals a uniform dispersion of $\mathrm{SiC}$ within $\mathrm{Cu} / 20 \mathrm{vol} \% \mathrm{SiC}$ microcomposite. 

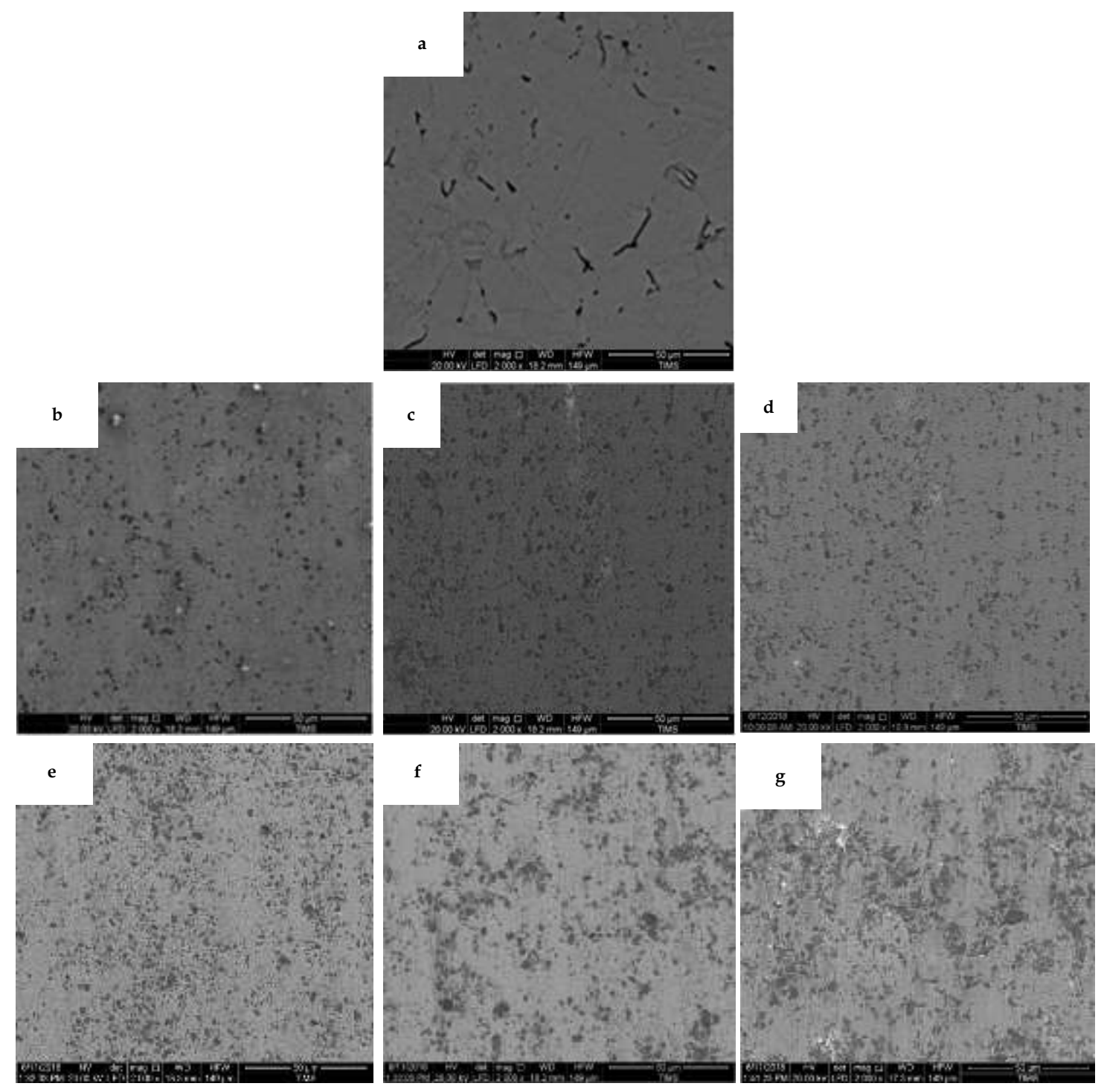

Figure 4(a-g) SEM Photographs Of Cu And SiC/Cu Microcomposites With Different SiC Contents $(0,5,10,15,20,25,30 \%)$ Sintered $A t 860^{\circ} \mathrm{C}$. 

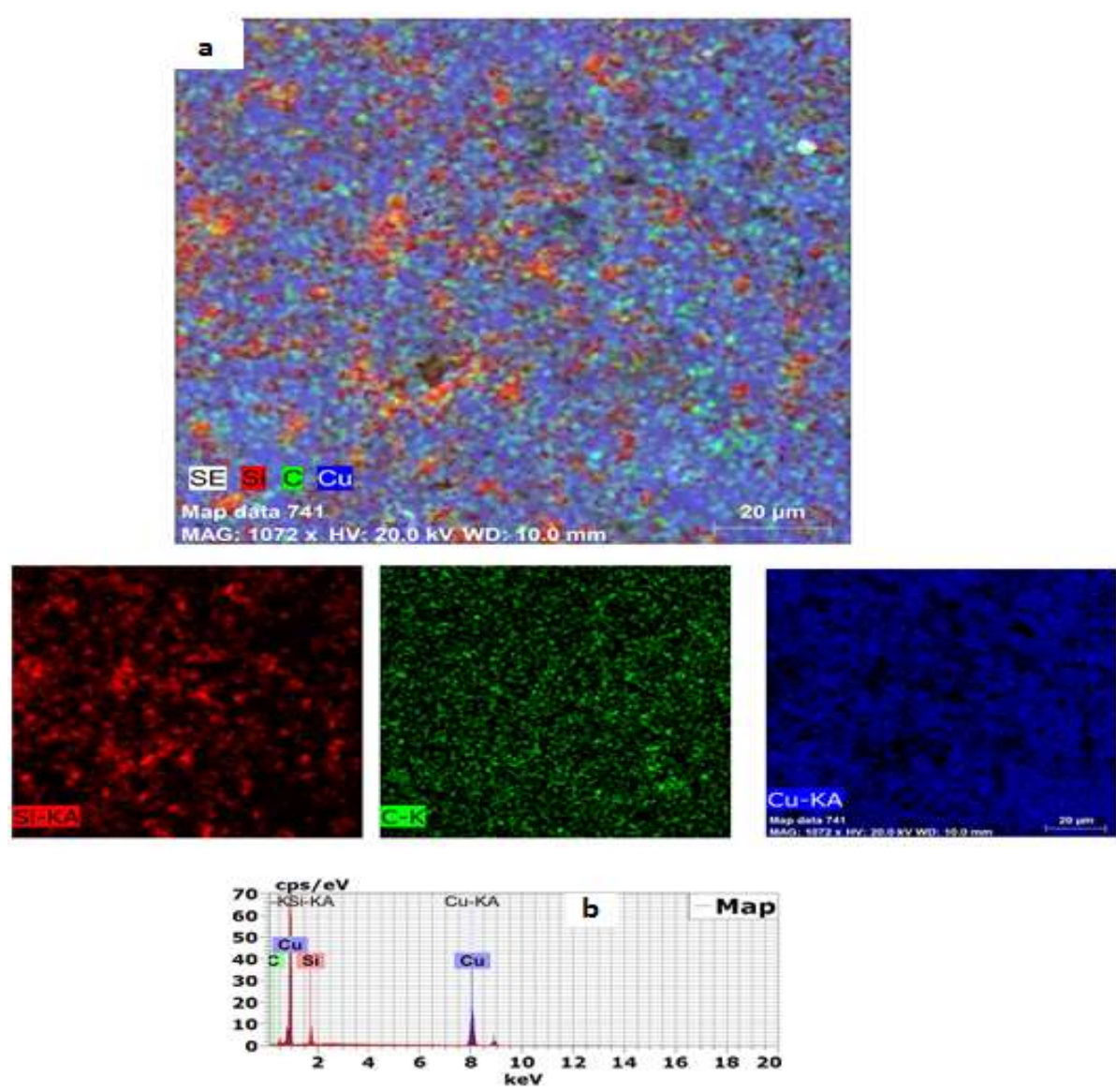

Figure 5. EDS Elemental Mapping Of The Of $\mathrm{Cu} / 20 \% \mathrm{SiC}$ Microcomposites a)The Corresponding Elemental Mapping Of $\mathrm{Si}, \mathrm{C}$ And Cu Respectively. b)EDS Spectrum Of $\mathrm{Cu} / 20 \% \mathrm{SiC}$.

\subsection{XRD analysis}

Fig. 6 shows the XRD spectrum of a $\mathrm{Cu} / \mathrm{SiC}$ microcomposite with various of volume fraction $\mathrm{SiC}$ particles. Due to the JCPDS XRD files, the reflection planes of (111), (200) and (220) at $2 \theta$ of $43.29,50.43,74.12$ respectively, assuring the formation of $\mathrm{Cu}$ face center cubic. The reflection planes of (100), (002), (101), (102), (110) at $2 \theta$ of 33.58, 35.50, 38.13 and 49.6760 .05 respectively, confirming the formation of hexagonal SiC particles. In addition, XRD analysis revealed that increasing $\mathrm{SiC}$ particles caused reduction in intensity of $\mathrm{Cu}$ peaks. According to Akbarpour et al. [12], the reduction in intensity is due to a differential in thermal expansion between the $\mathrm{Cu}$ matrix and the $\mathrm{SiC}$ particles, resulting in the creation of lattice micro-strain in the matrix. Also the behavior can be explained by the matrix's decreasing grain size. 


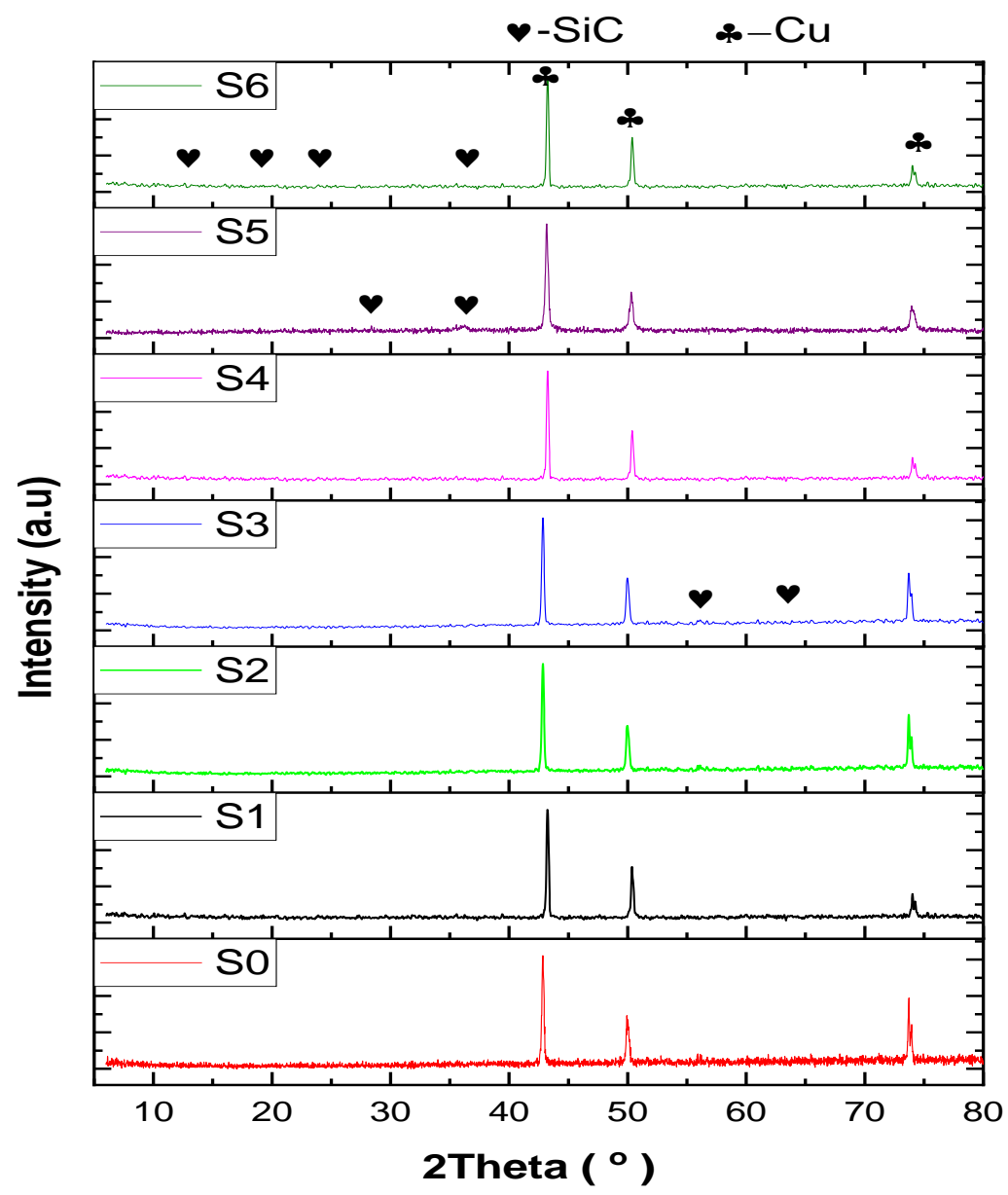

Figure 6. XRD Pattern Of The Cu/SiC Composite Reinforced With Different Volume Fraction Of SiC Particles

Furthermore, the crystallite size (d) and the lattice strain $(\eta)$ of $\alpha-\mathrm{Cu}$ material can be determined according to Williamson-Hall formula [12,14]:

$$
\beta \operatorname{Cos} \theta=\frac{k \lambda}{d}+4 \eta \operatorname{Sin} \theta
$$

Where $\mathrm{k}$ characterizes the Scherrer constant $((\mathrm{k}=0.9-1.0)), \lambda$ refers to $X$-ray wavelength and $\eta$ is the average of lattice strain, $\beta$ represents the full width at half maximum of the central peaks in radian, $\theta$ is Bragg angle. Plotting $\beta \cos \theta$ versus $\sin \theta$ for $((\alpha-\mathrm{Cu}))$ as shown in fig. 7. Gives a straight line with

slope of $(2 \eta)$ and intercept of $(\mathrm{k} \lambda / \mathrm{d})$.

The data which were used in Equation (2) obtained from Fig. 6. The crystallite size (d) and the lattice strain $(\eta)$ were plotted in the fig. 7. It was discovered that the outcomes had been reversed.. The crystallite size of $\alpha-\mathrm{Cu}$ matrix is decreased by $\sim 36,62,66$ and $72 \%$ for $5 \%, 10 \%, 15$ and $20 \%$ vol $\mathrm{SiC}$, 
respectively comparing with the pure $\mathrm{Cu}$ sample. Increasing $\mathrm{SiC}$ volume fraction to 25 and $30 \%$ vol, the average lattice strain and the crystallite size increased but still lower than pure $\mathrm{Cu}$. this behavior could be attributed to nonuniform dispersion of $\mathrm{SiC}$ within the matrix.

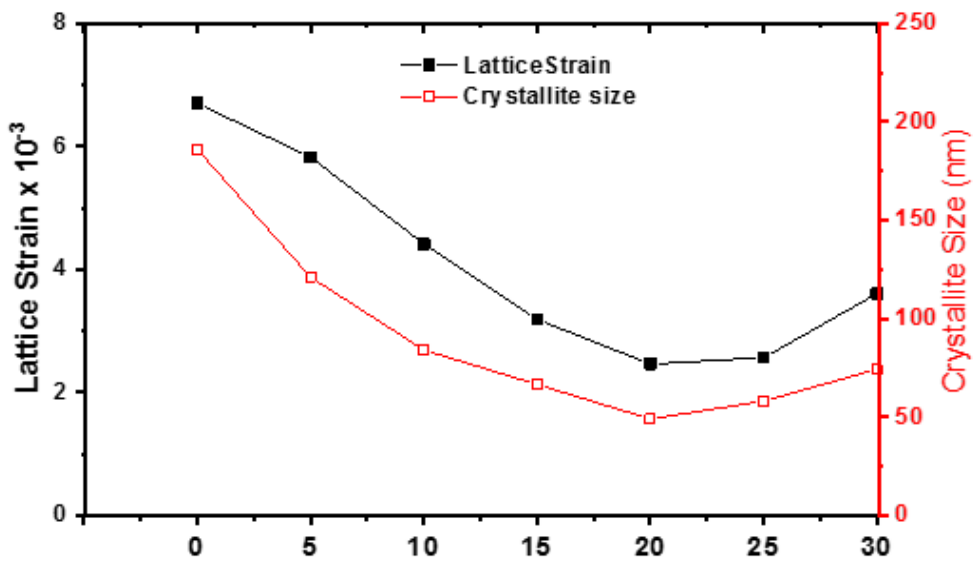

Figure 7. Effect Of SiC Volume Fractions On The Crystallite Size And Lattice Strain

\subsection{Mechanical properties}

\subsubsection{Hardness}

Hardness is an important mechanical characteristic for understanding composites' overall mechanical behaviour. The hardness of composites can be evaluated by several parameters, such as particles volume fraction, size of particle, distribution, density of reinforcement, and production method [15]. Fig. 8 (a-g) represents the color- contour maps of the hardness on the $\mathrm{Cu}$ pure and $\mathrm{Cu} / \mathrm{SiC}$ composite with different mass fraction of $\mathrm{SiC}$ particles. Variation in hardness magnitudes observed in all samples compared with pure $\mathrm{Cu}$ sample. The variations in hardness seem to be very low when the $\mathrm{SiC}$ mass fraction was $0 \%$. Hardness difference between the maximum value and minimum value was $67,149,151,154,156,141 \mathrm{HV}$ in the case of the $\mathrm{Cu}, \mathrm{Cu} / 5 \mathrm{vol} \% \mathrm{SiC}, \mathrm{Cu} / 10$ vol\% $\mathrm{SiC}, \mathrm{Cu}-15$ vol\% SiC, 20 vol\% $\mathrm{SiC}, \mathrm{Cu}-25$ vol\% $\mathrm{SiC}$ and $\mathrm{Cu}-30$ vol\% $\mathrm{SiC}$ respectively. The variations in hardness seem to be more significant when the $\mathrm{SiC}$ mass fraction was between 25 to $30 \%$. Also, fig $9(\mathrm{a}-\mathrm{g})$ shown that, the hardness value decreased from center to outside of sample. The variation in the value of hardness is due to the variation in the $\mathrm{SiC}$ particles distribution in the matrix or the difference in internal strain from the sample's core to the outer surface [16,17]. Fig. 9 presented the results of the hardness for the investigated samples. The outcomes revealed that the microcomposites hardness values were higher than the pure $\mathrm{Cu}$ specimen. The values became higher as the $\mathrm{SiC}$ volume fraction increased, and the hardness increased as well, reaching $231 \mathrm{HV}$ for the composite sample with $20 \% \mathrm{SiC}$ particles. The hardness was increased from $75 \%$ for $\mathrm{Cu} 20 \% \mathrm{SiC}$ composite compared with unrienforced $\mathrm{Cu}$. This increase in hardness was caused by the existence of hard $\mathrm{SiC}$ particles in the $\mathrm{Cu}$ matrix. In comparison to pure $\mathrm{Cu}$, it has been hypothesized that the addition of reinforcements in $\mathrm{Cu}$ composites may increase grain refinement even more $[18,19]$. On the other hand, the hardness results revealed significant decrease with the addition of 25 and $30 \%-\mathrm{SiC}$ 
particles. The average hardness values of microcomposite which contain 25 and $30 \% \mathrm{SiC}$ (217and $181 \mathrm{HV})$ as shown in Fig. 9 were obviously lower than that of the $\mathrm{Cu} / 20 \% \mathrm{SiC}(231 \mathrm{HV})$, indicating an inhomogeneous distribution of $\mathrm{SiC}$ reinforcement with the $\mathrm{Cu}$ matrix. Further, Fig. 4 shows the nonuniform arrangement of reinforcement particles and clusters of SiCp at higher volume fraction.
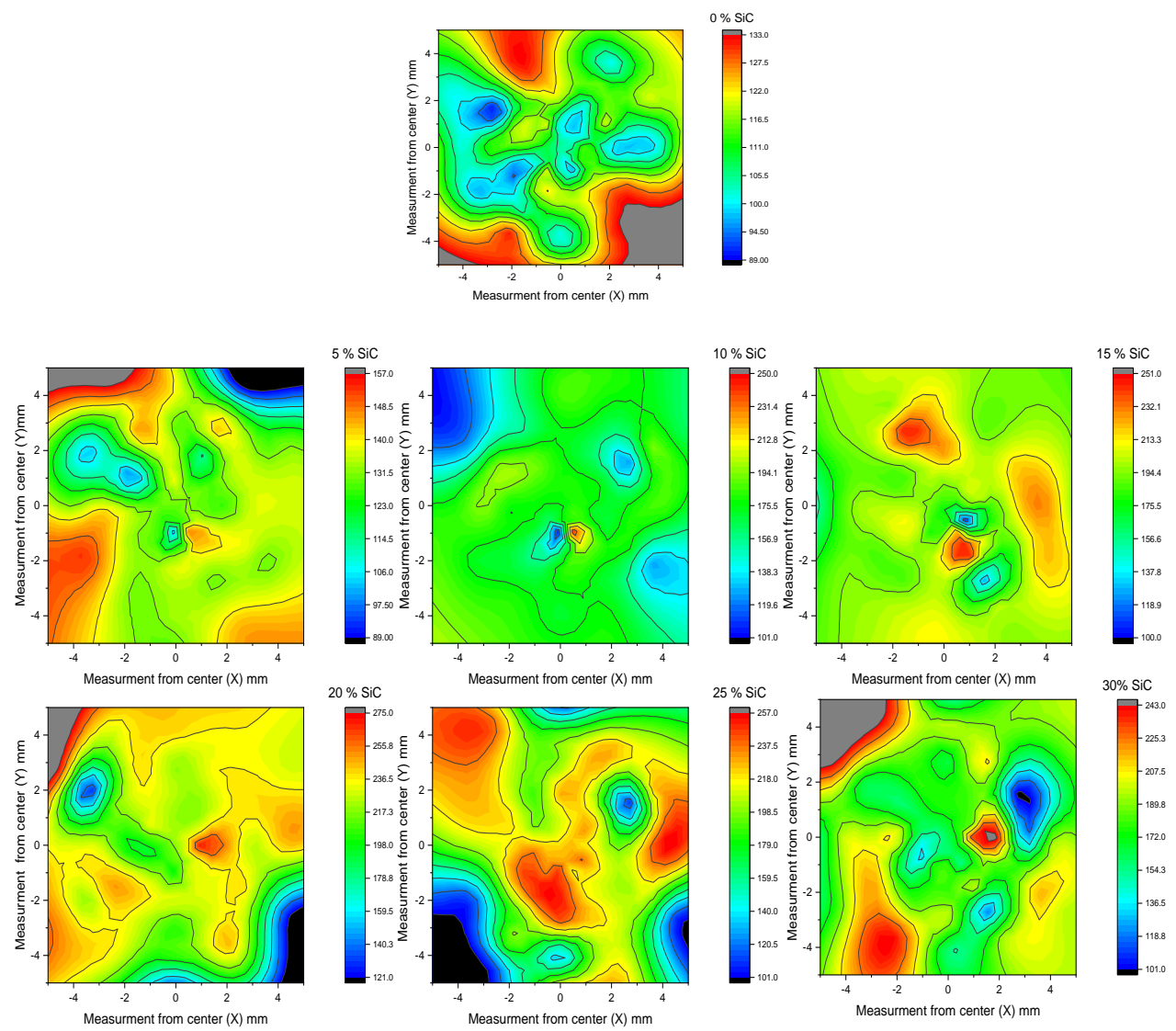

Figure 8. Show The Contour Map For Hardness Values Of $\mathrm{Cu} / \mathrm{SiC}$ Composites With Different SiC Contents $(0,5,10,15,20,25,30 \%)$ Resulted From Hardness Testing With Indentation Distance Of $1 \mathrm{~mm}$.

\subsubsection{Compressive strength}

Fig. 10 illustrated the compression stress-strain graphs for unrienforced $\mathrm{Cu}$ and $\mathrm{Cu} / \mathrm{SiC}$ microcomposites with various volume fractions of $\mathrm{SiC}$ reinforcement. Whereas ultimate compressive strength and compressive yield strength which extracted from fig 10 were showed in Fig 11 . The results revaled that, the micrcomposites had greater yield and ultimate strength than the unreinforced $\mathrm{Cu}$, as shown in Figs $10 \& 11$. The ultimate compressive and yield compressive strength were increased from $\sim 26.1 \%$ for unreinforced $\mathrm{Cu}$ to $\sim 57 \%$ for the $\mathrm{Cu} / 20 \mathrm{vol} \% \mathrm{SiC}$ microcomposite, respectively. as demonstrated in Fig. 11, increasing the $\mathrm{SiC}$ reinforcement inside the $\mathrm{Cu}$ matrix to 25 and 30 percent did not result in substantial gains in yield and ultimate composite strength when 
compared to the $\mathrm{Cu} / 20 \mathrm{vol} \% \mathrm{SiC}$ composite. The decrease in yield and ultimate compressive strength of the $\mathrm{Cu}$ reinforced with 25 and $30 \% \mathrm{SiC}$ composites comparing to $20 \mathrm{vol} \% \mathrm{SiC}$ can be attributed to the presence of certain clusters and nonuniform homogeneity of $\mathrm{SiC}$ particles inside the $\mathrm{Cu}$ matrix, as indicated in microstructure. This behavior caused a weak interfacial bonding. It is known that, the interface between the hard $\mathrm{SiC}$ reinforcement and the $\mathrm{Cu}$ matrix plays an important role in the mechanical properties of composites [20,21].

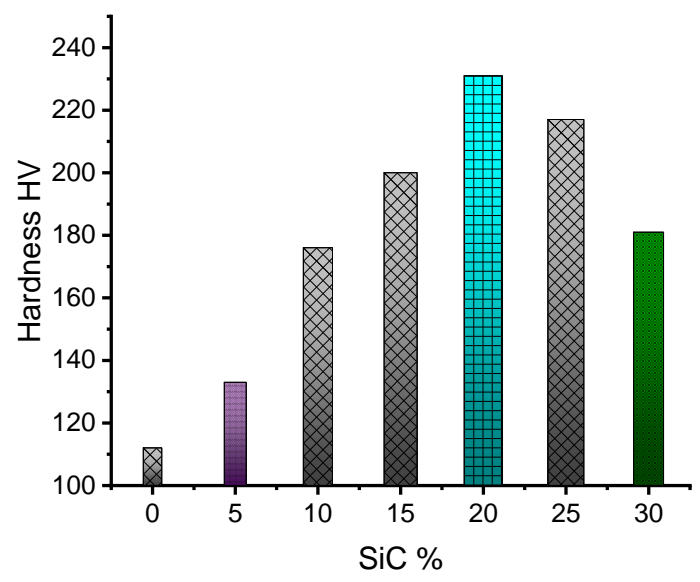

Figure 9 Hardness Of Cu / SiC Microcomposite With Various SiC Content.

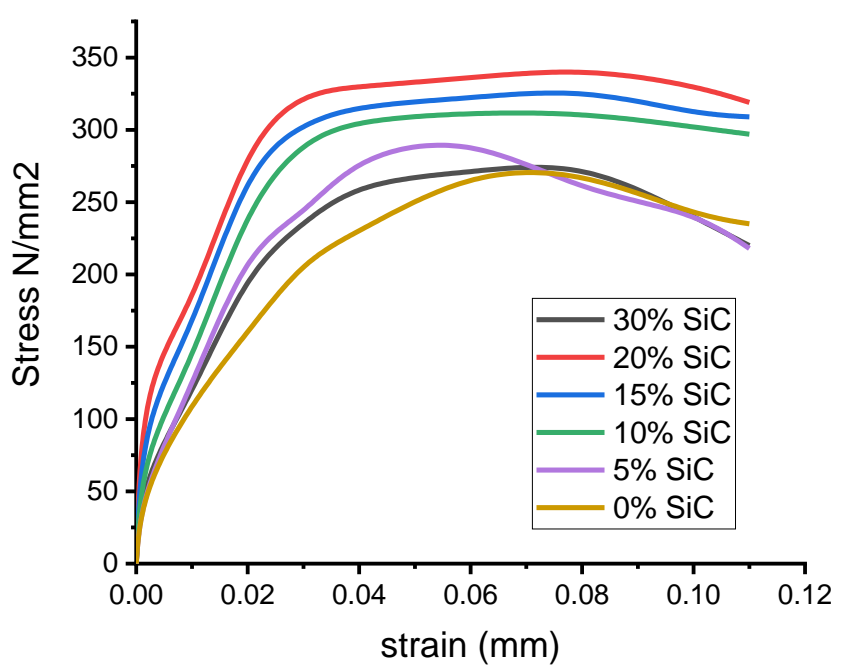

Figure 10. Compressive Stress-Strain Curves For The Cu/SiC Microcomposites. 


\subsubsection{Dislocation density measurements}

The following equation was used to determine the effect of $\mathrm{SiC}$ volume fraction on the dislocation density ( $\rho)$ of $\alpha-\mathrm{Cu}$ using an XRD pattern. [22].

$$
\rho=\frac{7.75 \times \eta}{b \times t}
$$

Where $(\eta)$ characterizes lattice strain, $(b=0.154 \mathrm{~nm})$ represents burger vector of $\mathrm{Cu}$ and $(\mathrm{t})$ signifies crystallize size.

The obtained results can be presented in Fig.. 12. It is obvious that increasing SiC content to 20 (vol. $\%$ ) increases the dislocation density according to increasing the lattice strain. When the tungsten was 15 vol\%, Arsenault and Shi [64] found that the lowest dislocation density within the matrix was $7 \times 10^{11}\left(\mathrm{~m}^{-2}\right)$, while at the $\mathrm{Cu}-\mathrm{W}$ interface, the dislocation density was $4 \times 10^{12}\left(\mathrm{~m}^{-2}\right)$. It was concluded that the variation in coefficient of thermal expansion (about 4:1) between copper and tungsten was shown to be the cause of the increasing dislocations. In our case the difference in the coefficient of thermal expansion between copper and $\mathrm{SiC}$ is 8:1 more than twice as great as in the $\mathrm{Cu}-\mathrm{W}$ system. On the other hand, Fig. 12 reveals that after $20 \% \mathrm{SiC}$, the dislocation density decreased, which can be related to the existence of $\mathrm{SiC}$ reinforcement agglomeration in the composites with 25 and $30 \% \mathrm{SiC}$, as demonstrated in the microstructure images previously. The dislocation density increased from $12 \times 10^{14}\left(\mathrm{~m}^{-2}\right)$ for pure copper to $37 \times 10^{14}\left(\mathrm{~m}^{-2}\right)$ by increasing $\mathrm{SiC}$ content to 20 (vol. $\%)$. However, the results observed that the dislocation density reduced to $32 \times 10^{14}$ and $30 \times 1014\left(\mathrm{~m}^{-2}\right)$ when $\mathrm{SiC}$ content increased to 25 and 30 (vol. \%) respectively.

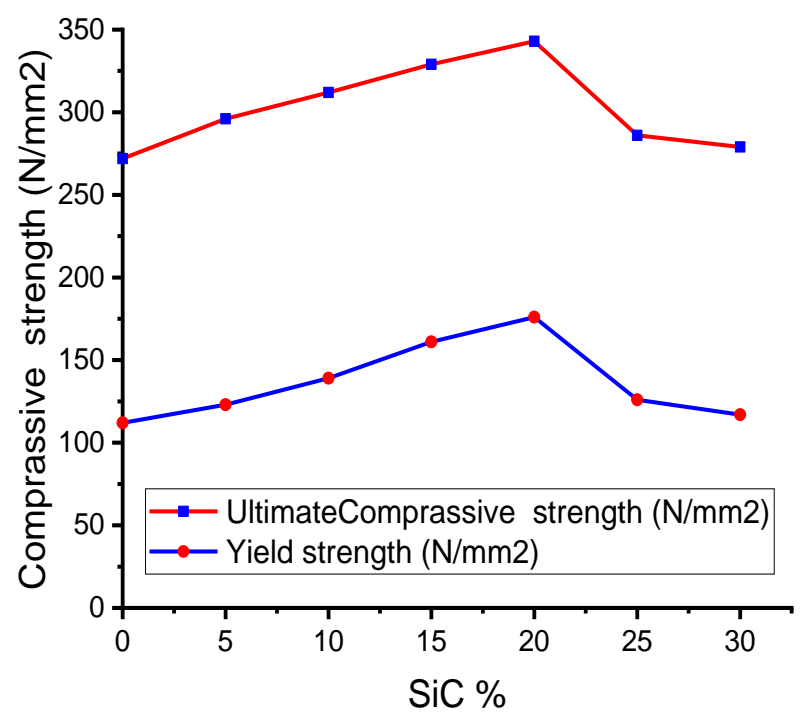

\section{Figure 11. Effect Of The SiC Content On The Yield And Ultimate Compressive Strength Of $\mathrm{Cu} / \mathrm{SiC}$ Micrcomposites.}

$\mathrm{Cu} / \mathrm{SiC}$ micrcomposites have improved in hardness, compressive yield, and ultimate strength for 
many reasons. The first reason may be related to the Apparent strengthening efficiency (Ra). Ra refers to the ratio of yield strength increase of the composite to that of the matrix. The following equation can be used to calculate apparent strengthening efficiency [23].

$$
\mathrm{Ra}=\frac{\sigma \mathrm{c}-\sigma \mathrm{m}}{\mathrm{V} f \boldsymbol{\sigma m}}
$$

Where $((\sigma \mathrm{m}))$ refer to the matrix yield; considering the difficulty to obtain an accurate value of the reference and $((\mathrm{V} f))$ is the volume fraction of the reinforcement particles, $((\sigma c))$ represents the composite yield strength,. Ra can characterizes the composite overall strength enhancement as a result of the reinforcement. According to the previous equation, the apparent strengthening efficiency (Ra) increases as the $\mathrm{SiC}$ volume fraction increases, accordingly, all mechanical properties will improve. The second reason is rule of mixture. As a simplistic model, the rule of mixture can only be apply roughly to estimate the mechanical characteristics of composites, and it is frequently inconsistent with experimental data. The Rule of mixture [24], can be expressed as follows:

$$
\sigma c=V m \sigma m+V f \sigma f
$$

According to the rule of mixture, with increasing the $\mathrm{SiC}$ volume fraction the strength will be increase.

The third reason is the transfer of load from $\mathrm{Cu}$ matrix to $\mathrm{SiC}$ reinforcement and interface bonding between matrix and $\mathrm{SiC}$ particles which are important to the strengthening of $\mathrm{Cu} / \mathrm{SiC}$ micrcomposites. When $\mathrm{Cu}$ matrix composite was loaded, the load was transferred from the $\mathrm{Cu}$ matrix to the $\mathrm{SiC}$ reinforcement particle, which increased the composite samples' resistance to plastic deformation due to the variation in thermal mismatch values of the matrix and reinforcement particles. This thermal mismatch caused increasing in dislocation density into the $\mathrm{Cu}$ matrix [25]. A higher dislocation density in the composite resulted in a higher degree of internal stress, which improved all of the composites mechanical properties.

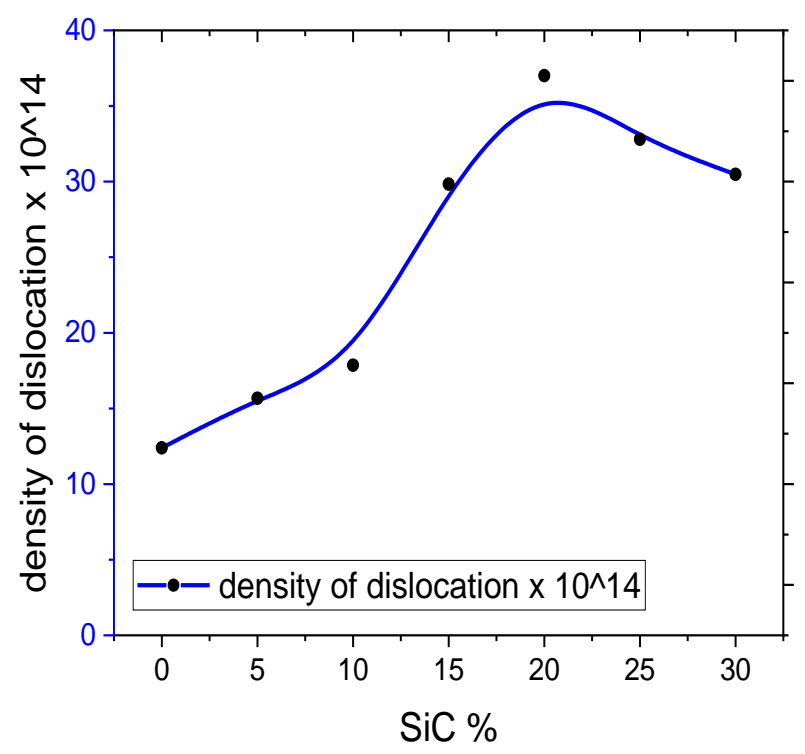

Figure 12. Effect of SiC Content on The Dislocation Density of Cu/SiC Micrcomposites. 


\section{Conclusion}

In the current research, $\mathrm{Cu}$ matrix reinforced with different volume fraction of micro-SiC particles was fabricated. The crystallite size of copper matrix was decreased with increment of $\mathrm{SiC}$ contents to 20 (vol \%) beyond this value, it was increased but still lower than the base matrix. SEM results showed a uniform distribution of $\mathrm{SiC}$ particles to 20 vol.\% $\mathrm{SiC}$. The dislocation density increased from $12 \times 10^{14}\left(\mathrm{~m}^{-2}\right)$ for pure copper to $37 \times 10^{14}\left(\mathrm{~m}^{-2}\right)$ by increasing $\mathrm{SiC}$ content to 20 (vol. $\%)$. However, the results showed that the dislocation density decreased to $32 \times 10^{14}$ and $30 \times 10^{14}\left(\mathrm{~m}^{-2}\right)$ when $\mathrm{SiC}$ content increased to 25 and 30 (vol. \%) respectively. Further, sample of 20 (vol. \%) SiC possesses the highest hardness, ultimate and yield compressive strength than that of the other six composites. The values of hardness, Ultimate and yield compressive strength increased to 231 $\mathrm{HV}, 343$ and $176 \mathrm{~N} / \mathrm{mm}^{2}$, respectively for the composite sample containing $20 \% \mathrm{SiC}$ particles with increasing percentage of $75 \%, 26.6 \%$ and $57.2 \%$ respectively, compared with pure $\mathrm{Cu}$.

\section{REFERENCES}

[1] K.M. Zohdy, M.M. Sadawy and M. Ghanem, "Corrosion behavior of leaded-bronze alloys in sea water" , Journal of Materials Chemistry and Physics., vol. 147, no. 3, (2014), pp. 878-883.

[2] H. Ming, Z. Yunlong, T. Lili, S. Lin, G. Jing, D. Peiling, " Surface modifying of SiC particles and performance analysis of $\mathrm{SiCp} / \mathrm{Cu}$ composites", Journal of Applied Surface Science., vol. 332, (2015), pp. 720-725.

[3] M. M. Sadawy, M. Ghanem," Grain refinement of bronze alloy by equal-channel angular pressing (ECAP) and its effect on corrosion behavior", Journal of Defence Technology., vol. 12, (2016), pp. 316-323.

[4] K. K. Alaneme, B. U. Odoni, " Mechanical properties, wear and corrosion behavior of copper matrix composites reinforced with steel machining chips", Journal of Engineering Science and Technology, an International Journal, vol. 19, (2016), pp. 1593-1599.

[5] M.A. Metwally, M. M. Sadawy, M. Ghanem, I.G.El-Batanony ",Effect of nano SiC particles on the characterization of $\mathrm{SiC} / \mathrm{Cu}$ nano-composite", Journal of Al-Azhar University Engineering Sector, vol. 16, no. 61, (2021), pp. 1118-1129.

[6] S.C. Tjong, K.C. Lau," Tribological behaviour of SiC particle-reinforced copper matrix composites", Journal of Materials Letters, vol. 43, (2000), pp. 274-280.

[7] M. Abd-Elmonem Metwally ,M.M. Sadawy, M. Ghanem , I .G.EL-Batanony, " Effect of $\mathrm{SiC}_{(\mathrm{p})}$ Content on the Corrosion Behavior of Nano $\mathrm{SiC}_{(\mathrm{p})} \mathrm{Cu}$ Composites", The Egyptian International Journal of Engineering Sciences and Technology, vol. 26, (2018), pp. 22-28.

[8] S.A Khadem, S. Nategh, H. Yoozbashizadeh," Structural and morphological evaluation of Al5vol. \% SiC nanocomposite powder produced by mechanical milling", Journal of Alloys and Compounds, vol. 509, (2011), pp. 2221-2226.

[9] M. Shabani, M. H. Paydar, R. Zamiri,M. Goodarzi, M. M. Moshksar," Microstructural and sliding wear behavior of SiC-particle reinforced copper matrix composites fabricated by sintering and sinter-forging processes", Journal of materials and technology, vol. 5, no. 1,(2016), pp. 5-12.

[10] G. Celebi Efe, T. Yener, I. Altinsoy, M. Ipek, S. Zeytin, C. Bindal, " The effect of sintering temperature on some properties of $\mathrm{Cu}-\mathrm{SiC}$ composite", Journal of Alloys and Compounds, vol. 509,(2011), pp. 6036-6042.

[11] N. Somania, N. Sharmab, A. Sharmab, Y. Kumar G. Paras K. Allanson A. Solomon," Fabrication of $\mathrm{Cu}-\mathrm{SiC}$ Composites using Powder Metallurgy Technique", .Materials Today: Proceedings. vol. 5,(2018), pp. 28136-28141. 
[12] M.R. Akbarpour, H. Mousa Mirabad, S. Alipour," Microstructural and mechanical characteristics of hybrid $\mathrm{SiC} / \mathrm{Cu}$ composites with nano- and micro-sized SiC particles", Journal of Ceramics International, vol. 45, (2019),pp. 3276-3283.

[13] A.S. Prosviryakov, " $\mathrm{SiC}$ content effect on the properties of $\mathrm{Cu}-\mathrm{SiC}$ composites produced by mechanical alloying", Journal of Alloys and Compounds, vol. 632,(2015),pp. 707-710

[14] K.S. Al-Rubaie, H.N. Yoshimura, J.D.B. de Mello, " Rietveld refinement, microstructural, optical and thermal parameters of zirconium titanate composites ",Ceramics International, vol. 44, (2018), pp. 1653-1661.

[15] S. Sankaranarayanan, V. H. Shankar, S. Jayalakshmi, N. Q. Bau, M. Gupta: Journal of Alloys \& Compounds, 627, 2015,192-199.

[16] E.Y. Yoon, D.J. Lee, D.H. Ahn, E.S. Lee, H.S. Kim, " Mechanical properties and thermal stability of bulk $\mathrm{Cu}$ cold consolidated from atomized powders by high pressure torsion ", Journal of Materials Science, vol. 4, no. 22, (2012), pp. 7770-7776.

[17] N. Lugo, N. Llorca, J.M. Cabrera, Z. Horita," Microstructures and mechanical properties of pure copper deformed severely by equal-channel angular pressing and high pressure torsion,", Journal of Material science and Enginerring:A, vol. 477, no. 1 ,(2008), pp. 366-371.

[18] Ashida M, Horita Z, Kita T, Kato A, " Production of Al/A12O3 nanocomposites through consolidation by high-pressure torsion", Journal of Materials Transactions, vol. 53, no. 1,(2012),pp. 13-6.

[19] Zhao L, Lu H, Gao Z," Microstructure and mechanical properties of Al/Graphene composite produced by high-pressure torsion", Journal of Advanced Engineering Materials, vol. 17, no. 7,(2015), pp. 976-81.

[20] A. Fukushima, C. Fujiwara, Y. Kagawa, C. Masuda," Effect of interfacial properties on tensile strength in SiC/Ti-15-3 composites.", Journal of Material Science \& Engineering: A, vol. 276,(2000), pp. 243-249.

[21] A. Urea, J.M. Gmez de Salazar, M.D. Escalera, " Influence of metal-ceramic interfaces on the behavior of metal matrix composites and their joints ", Key Engineering Materials, vol. 127-131, (1996),pp. 687-94.

[22] E.A. Eid, A.M. Deghady, A.N. Fouda, "Enhanced microstructural, thermal and tensile characteristics of heat treated Sn-5.0Sb-0.3Cu (SSC-503) Pb-free solder alloy under high pressure", Journal of Materials Science \& Engineering A, vol. 743, (2019), pp. 726-732.

[23] L.D. Wang, Y. Cui, B. Li, S. Yang, R.Y. Li, Z. Liu, R. Vajtai, W.D. Fei," High apparent strengthening efficiency for reduced graphene oxide in copper matrix composites produced by molecule-lever mixing and high-shear mixing", Journal of RSC Advances., vol. 5, no. 63,(2015), pp.51193.

[24] T.W. Clyne, P.J. Withers, "An introduction to metal matrix composite's, Beijing: Metallurgical Industry Press, (1996).

[25] M.R. Akbarpour, E. Salahi, F. Alikhani Hesari, A. Simchi, H.S. Kim," Fabrication, characterization and mechanical properties of $\mathrm{SiC}$ nanoparticles and carbon nanotube reinforced copper based hybrid composites", Journal of Material Science \& Engineering: A, vol. 572, (2013), pp. 83-90. 